\title{
The critical period of infant feeding for the development of early disparities in obesity
}

\author{
Amanda L. Thompson ${ }^{a, b},{ }^{*}$ and Margaret E. Bentley ${ }^{a, c}$ \\ aCarolina Population Center, University of North Carolina at Chapel Hill, USA \\ ${ }^{b}$ Department of Anthropology, University of North Carolina at Chapel Hill, USA \\ 'Department of Nutrition, Gillings School of Global Public Health, University of North Carolina at \\ Chapel Hill, USA
}

\begin{abstract}
Childhood obesity is an increasing public health problem, particularly among minority infants and young children. Disparities in overweight prevalence persist and widen with age, highlighting the need to identify factors contributing to early excess weight gain. We review the behavioral, social and macro-environmental factors contributing to the development of obesogenic early feeding practices among African-American infants and young children. We then examine the sociodemographic, household factors, feeding beliefs and infant characteristics associated with age-inappropriate feeding of liquids and solids (inappropriate feeding) among mothers and infants participating the U.S. Infant Care and Risk of Obesity Study, a cohort study of 217 low-income, first-time mothers and infants followed from 3 to 18 months of age. Maternal and infant anthropometry, infant diet, and maternal and household characteristics were collected at home visits at 3, 6, 9, 12 and 18 months of age. Mixed logistic regression was used to estimate the association between maternal and infant characteristics and inappropriate feeding. Rates of ageinappropriate feeding are high; over $75 \%$ of infants received solids or juice by 3 months of age. The odds of age-inappropriate feeding were higher among mothers who were single, depressed or believed that their infant is a "greedy" baby. Inappropriate feeding was associated with higher daily energy intake in infants $(\beta=109.28$ calories, $p=0.01)$ and with increased odds of high infant weight-for-length (WFL; OR $=1.74,95 \% \mathrm{CI}$ : 1.01-3.01). Our findings suggest that ageinappropriate complementary feeding influences current energy intakes and infant WFL, factors that may increase long-term obesity risk by shaping infant appetite, food preferences, and metabolism. Given the intractability of pediatric obesity, understanding the role of early feeding in shaping long-term health disparities is critical for developing prevention strategies to stem obesity in early childhood.
\end{abstract}

\section{Keywords}

Breastfeeding; Solid feeding; Obesity; African-American; Infancy; U.S.A.

\section{Introduction}

The prevalence of pediatric obesity has increased dramatically in recent years and AfricanAmerican infants and young children are at disproportionate risk. According to recent

\footnotetext{
(c) 2012 Elsevier Ltd. All rights reserved.

"Corresponding author. Department of Anthropology, University of North Carolina at Chapel Hill, 123 W Franklin St., CB\#8120 Chapel Hill, NC 27516, USA. Tel.: +1 919843 6255; fax: +1 919966 6638. althomps@email.unc.edu. .
} 
figures from the Pediatric Nutrition Surveillance Study, $10.4 \%$ of African-American infants aged 0-11 months and $15.8 \%$ of those aged 12-23 months have weights-for-length above the 95th percentile, levels higher than those seen in white infants (Polhamus et al., 2009). The gap in overweight prevalence persists and widens with age, particularly among women. By childhood and adolescence (ages 2-19), the prevalence of overweight in AfricanAmerican girls is $23.8 \%$ compared to $14.8 \%$ for non-Hispanic white girls (Ogden et al., 2006). By adulthood, African-American women have the highest rates of obesity, with $50.3 \%$ of reproductive-aged women being obese compared to $24.8 \%$ of white women (Ogden et al., 2006). This widening gap, the occurrence of obesity-related health problems at increasingly younger ages (Weiss et al., 2004), and the persistence of childhood obesity through the life course (Dietz, 1998) highlight the need to identify factors contributing to early excess weight gain.

The importance of early life exposures in shaping long-term risk of obesity and the development of concomitant cardiometabolic disease is increasingly recognized within social science and public health (Benyshek, 2007; Gillman, 2005). Positing that early life physical, social, familial, psychological and cultural environments become biologically embodied in the developing individual, the life course approach highlights the importance of context in shaping health trajectories and emphasizes the historical embeddedness of social experiences (Alwin \& Wray, 2005; Ben-Shlomo \& Kuh, 2002). This perspective is critical for understanding the impact of early life factors on health disparities in obesity rates; however, few studies with a life course perspective have explicitly focused on infant feeding as an important component of the early environment.

Accumulating evidence indicates that early life nutritional disparities are likely to explain some of the higher prevalence of pediatric obesity among minority groups (Perez-Escamilla $\&$ Bermudez, 2012). Breastfeeding initiation, exclusivity, and continuation, factors associated with moderately lower childhood obesity risk in a large number of studies (Arenz, Ruckerl, Koletzko, \& von Kries, 2004; Owen, Martin, Whincup, Smith, \& Cook, 2005), are significantly lower among African-American women (Scanlon et al., 2010). Similarly, the timing of solid food introduction may also increase obesity risk in early childhood (Huh, Rifas-Shiman, Taveras, Oken, \& Gillman, 2011; Moorcroft, Marshall, \& McCormick, 2011) and differ by race/ethnicity status (Burdette, Whitaker, Hall, \& Daniels, 2006). The confounding effects of what is fed to infants have less often been considered, but social gradients in diet quality emerge early in childhood (Smithers, Golley, Brazionis, \& Lynch, 2011). Further, in addition to their nutritive effects, early feeding practices shape long-term eating and health behaviors by teaching children how, what, when and how much to eat and transmitting cultural and familial beliefs, attitudes, and practices surrounding food and eating (Birch \& Fisher, 1998). Parents and caregivers play a key role in structuring early feeding, which, in turn, is embedded in the larger micro- and macro-environments that shape parental beliefs, decisions and practices (Savage, Fisher, \& Birch, 2007).

Identifying the feeding practices that place infants and young children at risk for the development of obesity is important for determining which factors of the early environment can be modified and thus are amenable to intervention. In this paper, we first review the demographic, structural, and sociocultural factors contributing to obesogenic early feeding practices among African-American mothers focusing on factors associated with breastfeeding initiation and duration. This literature review informs our primary analysis testing whether similar factors influence the age-inappropriate feeding of solids and liquids in firsttime, low-income African-American mothers in central North Carolina participating in the Infant Care Study (Slining, Adair, Goldman, Borja, \& Bentley, 2010; Thompson et al., 2009; Wasser et al., 2011). Finally, we test whether inappropriate feeding is associated with greater energy intake and high weight-for-length (WFL) in infancy with the goal of 
identifying whether inappropriate feeding acts as a potentially modifiable risk factor in the development of early childhood overweight.

\section{Part 1: Review of the structural and sociocultural determinants of breastfeeding}

\section{Demographic and structural determinants of infant feeding}

National breastfeeding rates differ by race/ethnicity (Li, Darling, Maurice, Barker, \& Grummer-Strawn, 2005; Singh, Kogan, \& Dee, 2007) with 54.4\% of African-American women initiating breast-feeding and $26.6 \%$ breastfeeding to 6 months compared to $74.3 \%$ and $43.4 \%$ of white women, respectively (Scanlon et al., 2010). These racial/ethnic differences are greatly reduced, however, when controlling for socioeconomic status or maternal education. While markedly lower among low-income mothers participating in the federal Women, Infants and Children (WIC) supplemental nutrition program (McCann, Baydar, \& Williams, 2007), breastfeeding rates do not significantly differ between white and African-American participants (Hurley, Black, Papas, \& Caufield, 2008). Breastfeeding initiation also does not differ by maternal race/ethnicity among higher income women with access to breastfeeding-supportive health systems (Celi, Rich-Edwards, Richardson, Kleinman, \& Gillman, 2005). Along with income, maternal education is a strong predictor of breastfeeding initiation and duration (Forste, Weiss, \& Lippincott, 2001; Wright, Bauer, Naylor, Sutcliffe, \& Clark, 1998). In the nationally-representative Feeding Infants and Toddler Study (FITS), having a college education was more strongly associated with positive feeding behaviors than any other maternal characteristic with college-educated mothers more likely to follow American Academy of Pediatrics (AAP) breastfeeding and solid-feeding recommendations (Hendricks, Briefel, Novak, \& Ziegler, 2006).

Yet some persistent racial and ethnic differences in feeding remain when income and education are taken into account. In their analysis of data from the National Family Growth Study, Forste et al. (2001) found that white mothers were more likely to have the characteristics associated with the decision to breastfeed -higher income and education levels, marriage, living in the West and having a planned pregnancy-than were black women. These differences resulted in a strong racial disparity in breastfeeding, with African-American women $40 \%$ less likely to breastfeed than white women. While finding no difference in breastfeeding practices by race, Hurley et al. (2008) also found that AfricanAmerican women, who have a higher rate of single motherhood, were more likely to report the need to return to work as a reason for breast-feeding cessation than white mothers. Welfare reform and the requirement that women receiving welfare return to work before 6 months postpartum have also been linked to shorter breastfeeding duration (Haider, Jacknowitz, \& Schoeni, 2002).

Ethnographic research among low-income African American women has identified financial hardship, fears for safety and stress as important factors shaping their daily parenting decisions (Bentley, Gavin, Black, \& Teti, 1999; Cricco-Lizza, 2004). African-American women attending a WIC clinic in inner-city New York recounted how they struggled with the effects of poverty and discrimination on a daily basis, struggles that, in turn, influenced their perceptions of breastfeeding and child care (Cricco-Lizza, 2004). Mothers felt that infants needed to be strong and independent and were concerned that breastfed infants would be too "lazy" or "spoiled" and, thus, unable to survive in their dangerous neighborhoods. 


\section{Sociocultural determinants of infant feeding}

These continuing disparities highlight the importance of the numerous structural factors shaping the communities in which mothers live, communities which in turn shape maternal feeding decisions. Social support plays a key role in the initiation and continuation of breastfeeding (Cricco-Lizza, 2004) and cultural beliefs, shared through kin, friend and neighbor networks, may serve to promote or limit breastfeeding. Fathers' and grandmothers' opinions strongly, and contrastingly, influence breastfeeding initiation and duration (Avery \& Magnus, 2011). Fathers' support of breastfeeding, for example, was associated with a 12fold higher intention to breastfeed in an urban African-American sample (Mahoney \& James, 2000). Infants' grandmothers, on the hand, may promote early solid feeding or putting cereal in the bottle due to concerns that milk "runs right through" and is not enough to satisfy the needs of a "greedy" baby, even if this advice conflicts with that received from medical professionals (Bentley et al., 1999). Advice from family and friends may be more highly valued than that of healthcare providers, who themselves may be less likely to advise African-American women to breastfeed and more likely to provide advice about bottle feeding (Sharps, El-Mohandes, Nabil El-Khorazaty, Kiely, \& Walker, 2003).

The devaluation of breastfeeding and preference for formula feeding has a complex history in African-American communities. Forced wet-nursing during slavery, the inability to purchase expensive breastmilk substitutes during the rise of "scientific motherhood" in the 1950's and 1960's (Asiodu \& Flaskerud, 2011), and concerns that breastmilk transmits harmful substances from poor maternal diets, alcohol use, or smoking (Kaufman, Deenadayalan, \& Karpati, 2010) have contributed to a preference for formula feeding. Increased access to formula, whose legitimacy and potency was bolstered by WIC subsidies and hospital distribution, beginning in the 1970s (Kaufman et al., 2010) has contributed to generational histories of formula feeding and lack of breastfeeding role models in the community. Instead, the view that breastfeeding is "nasty", a sexual, morally suspect practice (Corbett, 2000), engenders embarrassment over breastfeeding in front of relatives and friends (Bentley et al., 1999) and concerns that public breastfeeding may lead to sexual violence (Bentley, Dee, \& Jensen, 2003; Kaufman et al., 2010). Coupled with structural factors leading to over-crowded housing with limited private space for mothers to breastfeed, such cultural perceptions lead to earlier termination of breastfeeding (Robinson \& VandeVusse, 2011).

\section{Part 2: Structural and sociocultural determinants of solid feeding: The Infant Care and Risk of Obesity Study (Infant Care)}

\section{Study design and subjects}

Given these strong structural and sociocultural influences on breastfeeding, we tested whether similar factors shape the timing and quality of solid feeding, an important but less well understood early feeding practice that may also contribute to overweight in infancy and childhood (Moorcroft et al., 2011). Infant Care is an observational cohort study examining risk factors for the development of obesity in the first 18 months of life among low-income African American mother and infant dyads. First-time mothers, aged 18-35 years, were recruited from WIC clinics in central North Carolina. All mothers were WIC eligible, meeting the state eligibility criteria of a household income $<185 \%$ of the U.S. Poverty Income Guidelines. 217 mothers and infants participated at the 3-month baseline home visit (mean infant age: 3.24 months, range: $2.7-4.2$ months) and were followed in-home when the infants were 6, 9,12 and 18 months of age. Data were collected between 2003 and 2007. The study protocol was approved by the Institutional Review Board of the University of North Carolina at Chapel Hill. 


\section{Study measures}

At each home visit, a wide array of maternal, infant, and household characteristics were assessed through questionnaires. Maternal characteristics included: age, education, depressive symptoms (a score >=16 on the Center for Epidemiologic Studies Depression Scale, CES-D; Radloff, 1977), marital status, and employment. Household characteristics included: household size and composition, perceived neighborhood safety (a continuous score ranging from 1 to 4 on the validated "Safety from Crime" sub-scale of the Neighborhood Environment Walkability Scale; Saelens, Sallis, Black, \& Chen, 2003), and food security (based on the US Department of Agriculture Core Food Security Module and a scoring schema devised by Laraia, Borja, and Bentley (2009) for this sample). Maternal feeding and health beliefs were assessed by questions (listed in Table 1) such as "Infants fed too soonwill be fat" or "I am concerned my infant will be overweight" and scored on a 5response Likert-type scale ranging from "strongly disagree" to "strongly agree." Because of the limited number of responses at the extremes of the scale, these variables were dichotomized with " 1 " indicating agreement/strong agreement and " 0 " indicating neutrality, disagreement or strong disagreement.

\section{Infant feeding}

Infant diet was measured at each home visit using two measures: an infant diet history (IDH) and 24-h dietary recalls (DR). Similar to other studies of infant feeding (Ponza, Devaney, Ziegler, Reidy, \& Squatrito, 2004), the IDH was used to measure the introduction and frequency of consumption of a number of foods and beverages. The IDH was provided at each study visit and mothers were asked to recall the frequency of food/liquid consumption during the study visit month, prior to study enrollment (months 0-3) at the 3-month visit, and in the months in between visits at subsequent visits (e.g. months 4-6 at the 6-month visit). The IDH was used to define age-inappropriate feeding of liquids and solids based on AAP guidelines for optimal feeding (AAP, 2008). Feeding is considered inappropriate if the infant receives: at 3 months, any liquids or solids except for breastmilk or formula; at 6 months, cow's milk or soy milk instead of human milk or formula, or juice, meat, eggs, cheese, junk food (such as potato chips, corn chips, or cheese puffs), fast food (such as French fries, chicken nuggets, burgers or pizza) or sweets (such as cookies, cakes, pies, or ice creams); at 9 months, cow's milk or soy milk, junk food, fast food or sweets; and at 12 or 18 months, flavored milks, junk food, fast food, or sweets.

Infants' mean daily energy intake from non-breastmilk liquids and solids was estimated through three 24-h DRs collected using the Nutrition Data System for Research software (NDS-R; version 2005 developed by the Nutrition Coordinating Center, University of Minnesota, Minneapolis, MN) at 3, 6, 9, 12, and 18 months. Details of this procedure have been published previously (Wasser et al., 2011). Briefly, the first DR was conducted during the home visit, using food models and pictures to aid in the estimation of portion sizes, and two subsequent telephone DRs were collected on random, nonconsecutive days within a 2week interval.

\section{Anthropometry}

Trained study personnel collected maternal and infant anthropometrics using standard techniques. At each visit, infant weight was measured on a digital scale (Tanita BD-585 Digital Baby Scale) to the nearest $10 \mathrm{~g}$ and recumbent length was measured to the nearest $0.1 \mathrm{~cm}$ with a portable length board (O'Leary Length Board). Maternal height and weight were measured at the 3-month visit using a stadiometer (Harpenden) to the nearest $0.1 \mathrm{~cm}$ and a digital scale (Seca 761) to the nearest $0.1 \mathrm{~kg}$. All anthropometric measurements were done in triplicate and the mean of these measures was used in analysis. Infant weight-forlength percentiles (WFL) were calculated using the CDC/NCHS 2000 growth reference 
(Ogden et al., 2002). We defined high infant WFL as WFL above the age- and sex-specific 90th percentile based on sample distribution (approximately $25 \%$ of infants were above this cut-point at each study visit) and for consistency with previously published papers from this sample (Slining et al., 2010). Maternal body mass index was calculated as weight (kg)/ height $(\mathrm{m})^{2}$. Maternal obesity was defined as a BMI $>30 \mathrm{~kg} / \mathrm{m}^{2}$.

\section{Analysis}

Descriptive statistics were used to assess the types of foods and liquids offered to infants and young children. We tested the structural and sociocultural predictors of age-inappropriate solid foods and liquids through a series of mixed effects logistic regression models. First, models were fit for each set of variables (maternal, infant, and household characteristics, sources of feeding information, and maternal feeding and health beliefs) and the dependent variable (inappropriate feeding), controlling for maternal age, infant age and sex, and repeated measures across subjects (Fig. 1). Next, significant variables from these component models were included in a final model, also controlling for maternal age, infant age and sex, and repeated measures across subjects. Effect modification was examined for all models through likelihood ratio testing of interaction terms and confounding was assessed through a priori change in estimate criterion (change in main effect coefficient of $>10 \%$ ).

To test the consequences of inappropriate intake on infant energy intake and high WFL (Fig. 1), we used mixed effects linear and logistic regression models (linear regression for energy intake and logistic regression for high WFL) controlling for repeated measures across subjects. The model predicting infant energy intake included covariates previously associated with energy intake in infants (weight, age, sex and activity) and an interaction term between inappropriate feeding and infant age. Infant activity, a continuous measure ranging from 1 to 7 with a higher score indicating a more active infant, was measured using the 16-item activity subscale of the Infant Behavior Questionnaire-Revised (IBQ-R; Gartstein \& Rothbart, 2003). This model was restricted to non-breastfed infants due to the difficulty of estimating energy intake from breastmilk; however, since mixed models are able to handle unbalanced observations, infants were excluded from analysis only for visits when they received breastmilk, resulting in the exclusion of 49 infants at 3 months, 25 infants at 6 months, 20 infants at 9 months, 8 infants at 12 months and 3 infants at 18 months. The model predicting high WFL controlled for infant activity, age, sex, breastfeeding status, and birth weight. Effect modification and confounding by maternal age and obesity was examined in both models. Neither maternal age nor obesity was a confounder or an effect modifier and was not included in the final models. Stata11 was used for all analyses.

\section{Results}

\section{Sample characteristics}

Mothers in this low-income sample were young ( $28 \%<20$ years of age), unmarried ( $89 \%)$, and obese (44\%; Table 1). Household size ranged from 2 to 13, with one-third of mothers living with the baby's father and $44 \%$ living with the infant's grandmother at the 3-month baseline visit. Nearly half the sample was at least marginally food insecure, experiencing food unavailability and/or hunger due to lack of money in the past 12 months, and almost $30 \%$ of mothers had scores indicating depressive symptomology.

\section{Infant feeding patterns}

$70 \%$ of mothers initiated breastfeeding and $25 \%$ of infants received breastmilk at the 3month visit. The proportion of inappropriate feeding was high, particularly at earlier ages. $78 \%(N=167)$ of infants received age-inappropriate solids and liquids at the 3 -month visit 
declining to $32 \%(N=35)$ at the 18 -month visit. Infant cereal was the most commonly provided complementary food at 3 months though approximately $20 \%$ of infants also received jarred infant vegetables, jarred infant fruits and non-infant solids, including chips, French fries, mashed potatoes, maple syrup and ice cream (Fig. 2). Of the 119 infants receiving cereal at 3 months, $85 \%(n=101)$ received cereal mixed with formula and/or breastmilk and fed in the bottle. Juice consumption was also high; $62 \%$ of infants received juice before 6 months with $10 \%$ receiving juice as early as the 2nd month of life (Fig. 3). Soft drinks and sweetened iced tea were also introduced before 12 months of age and, by 18 months, the consumption of soda and tea was over 10 times higher than breastmilk.

\section{Infant feeding beliefs and sources of feeding information}

Two-thirds of mothers agreed that breastmilk was enough to fill a baby at the 3-month home visit; however, only a few mothers believed that breastfeeding benefited infants by preventing obesity, improving health or improving IQ (Table 1). Fewer than half of mothers thought that feeding infants too much or too early would lead to overweight. More mothers reported asking their own mothers and their physicians for solid feeding advice than asking their friends or consulting parenting books.

\section{Factors associated with inappropriate feeding}

Several demographic/structural and sociocultural factors were significantly associated with inappropriate feeding. Among the demographic and structural variables (Table 1, models 13 ), single motherhood and maternal depressive symptoms were associated with increased odds of inappropriate feeding while the presence of the infant's father in the home and current breastfeeding were associated with reduced odds of inappropriate feeding. Among the sociocultural variables (Table 1, models 4-6), the belief that an infant who is overfed will be overweight and the belief that the infant is a "greedy" baby were associated with greater odds of inappropriate feeding while the belief that the infant will "eat anything" was associated with reduced odds in the component models. With the exceptions of maternal depressive symptoms, which was no longer significant at the $p<0.05$ level, and fathers' presence, which was highly co-linear with single motherhood and not included in the final model based on model fit indices (not shown), these demographic and social factors remained independently predictive of inappropriate feeding the final full model including all significant predictors from the component models and controlling for maternal age and infant age and sex (Table 1, "Full Model").

\section{Inappropriate feeding, infant energy intake and high WFL}

Inappropriate feeding was associated with a higher mean daily energy intake of over 100 calories in non-breastfed infants ( $\beta=109.28, p=0.01)$ and with greater odds of high WFL (odds ratio: 1.74; 95\% CI: 1.01-3.01) across infancy in adjusted models, compared to infants fed according to recommendations (Table 2).

\section{Discussion}

This analysis of early feeding practices among low-income African American infants documents low levels of breastfeeding, high levels of early solid and juice introduction, and age-inappropriate feeding practices. The prevalence of breastfeeding at 6 months (14.6\%) was much lower than the national prevalence (Scanlon et al., 2010) while the proportion of infants receiving solids and liquids (78\%) was higher than national estimates for black infants (Grummer-Strawn \& Mei, 2004; Ponza et al., 2004). These differences likely stem from the confluence of risk factors in our sample including low-income, low levels of maternal education, WIC participation and Southeastern residence (Li et al., 2005). The high prevalence of sugar-sweetened beverage consumption, nearly $25 \%$ at 18 -months, is 
particularly concerning given the tendency for these beverages to displace healthier options, such as 100\% fruit juice and milk, in toddler diets (Skinner, Ziegler, \& Ponza, 2004) and the links between excess juice and soda consumption and childhood obesity (Taveras, Gillman, Kleinman, Rich-Edwards, \& Rifas-Shiman, 2010).

Unlike the previous research on racial/ethnic differences in breastfeeding practices described in our review of the literature, structural factors (household size, neighborhood safety, and food insecurity) and social networks (presence of grandmothers in the household and sources of feeding advice) had limited impact on solid feeding practices in our sample of low-income African-American mothers. Inappropriate feeding was associated with several maternal sociodemographic and psychosocial characteristics, including marital status, presence of the infants' father in the home, and depressive symptoms. Similar to previous studies documenting that marital status and the involvement of fathers predict higher levels of breastfeeding (Mahoney \& James, 2000) and greater likelihood of following feeding recommendations (Hendricks et al., 2006), we found that single mothers were more likely to provide inappropriate foods and liquids during infancy and, conversely, that mothers living with the infant's father were less likely to inappropriately feed. Maternal depression, which has previously been linked to increased likelihood of early juice introduction in this sample (Wasser et al., 2011) and to a range of obesogenic infant care behaviors in other studies, including limited breastfeeding (McLearn, Minkovitz, Strobino, Marks, \& Hou, 2006a), bottle-propping (Dennis \& McQueen, 2007), and higher infant television exposure (McLearn, Minkovitz, Strobino, Marks, \& Hou, 2006b), was associated with higher odds of inappropriate feeding, though this result was somewhat attenuated when controlling for marital status, breastfeeding, and feeding beliefs.

Cultural beliefs that "greedy" infants are healthier also influenced maternal feeding practices, suggesting that mothers were influenced by feeding beliefs present in the community, even if we were not able to document a direct impact of advice provided by grandmothers, family members or friends on feeding practices. The positive associations between the beliefs that an infant fed too much will be fat and the infant is a "greedy" baby and inappropriate feeding seem counter-intuitive, but previous ethnographic research has documented that both larger infant size and "greediness" have positive cultural meanings, used to describe vigorous, healthy infants (Heinig et al., 2006). Such beliefs have been proposed to underlie African-American mothers' preference for larger infants and possibly to encourage inappropriate feeding (Baughcum, Burklow, Deeks, Powers, \& Whitaker, 1998). The perception that the infant will "eat anything" was associated with reduced odds inappropriate feeding in our sample. The link between a lack of perceived infant fussiness and fruit and vegetable consumption, i.e. healthy infant feeding patterns, has not been previously explored in African-American infants; however, the inverse, that fruit and vegetable consumption is lower among children perceived as picky, is seen in AfricanAmerican toddlers (Horodynski, Stommel, Brophy-Herb, Xie, \& Weatherspoon, 2010).

Few studies have examined the effect of early diet quality on overweight in infancy and early childhood and results are mixed among those that have (Smithers et al., 2011). Our results document that age-inappropriate feeding patterns contribute to increased energy intake in non-breasted infants and greater odds of high WFL, factors that may place infants at later risk for childhood obesity. Excess energy intake and poor early diet quality may promote excess weight gain, providing infants with higher than needed intakes of energy and protein, both of which have been linked to higher BMI in childhood (Koletzko et al., 2009). Exposure to such obesogenic early diets may also influence appetite regulation, entraining the hypothalamic neural circuitry regulating appetite by inducing permanent changes in the complex pathway linking the hypothalamus, gastrointestinal tract and adipose tissue (Agostoni, 2005). While we are unable to examine the long-term effects of this excess 
intake in our sample of infants, previous research documents an association between early energy intake and later risk of overweight. Among infants in the UK, for example, each additional $100 \mathrm{kcal} /$ day consumed at four months was associated with $46 \%$ higher odds of overweight at 3 years and 25\% higher odds at 5 years (Ong, Emmett, Noble, Ness, \& Dunger, 2006).

While the Infant Care Study provides the unique opportunity to longitudinally explore a wide-range of maternal, household, and sociocultural factors influencing infant feeding, it also presents some limitations. Compared to previous examinations of disparities in breastfeeding, relatively few structural or social factors predicted inappropriate complementary feeding, possibly due to our relatively small sample size or limited heterogeneity within our exclusively low-income African-American sample. Despite the best efforts of study personnel to contact participating mothers, the sample had a high attrition rate -only $64 \%$ of the sample $(n=139)$ remained at the 18 -month visit-as the instability of this relatively young, low-income sample made follow-up difficult. The main variables of interest, maternal and household characteristics, feeding beliefs, inappropriate feeding, and infant weight status, did not differ at 3 months age among those lost to followup. The relatively small number of infants remaining at 18 months limited our ability to examine the impact of early inappropriate feeding on later overweight in lagged models or to use the standard definition of overweight (weight-for-length >95th percentile). Our use of a 90th percentile cut-off increased the number of infants defined as high WFL at each visit to approximately $25 \%$ of the sample. While this improved model stability, this less stringent cut-point limits generalizability to other studies. Nonetheless, our results showing increased odds of high infant WFL with inappropriate feeding across infancy indicate that the timing and quality of complementary feeding merits further investigation.

\section{Conclusion}

Our findings that age-inappropriate feeding was associated with higher energy intake and increased odds of high WFL suggest that the structural and social characteristics of early solid feeding practices have the potential to shape the development of obesity in early childhood. Our findings also suggest that interventions aimed at improving the social and physical characteristics of the very early food environment may be critically important for reversing this development. Despite the high levels of early solid feeding and poor diet quality observed, levels of inappropriate feeding in our sample remain relatively stable after 3 months of age, and breast-feeding is associated with lower odds of inappropriate feeding of solids and liquids. Early interventions that focus on creating more positive attitudes toward breastfeeding, increasing social support for breastfeeding mothers, and supporting mothers' breastfeeding self-efficacy have been successful in increasing breastfeeding initiation and duration (Noel-Weiss, Rupp, Cragg, Bassett, \& Woodend, 2006). Similar attention to these potentially modifiable factors, feeding support and self-efficacy, may also improve the timing and quality of early complementary diets. Our results also document that mothers face significant barriers, including low socioeconomic status, single motherhood, and depression, which may limit their ability to meet solid feeding guidelines, and that these barriers will also require attention.

The importance of both individual-level factors and larger structural forces in shaping infant feeding practices highlights the need to examine the individual, household, community and societal factors that become embedded in individual biology (Braveman, 2009) and to intervene at each level to stem lifelong disparities in obesity and its biological and social sequelae. Given the persistent nature of pediatric obesity and the failure of interventions focusing on the individual to enact long-term change (Kumanyika, 2008), understanding the role of early feeding in shaping long-term health inequalities and the factors that can be 
modified to improve the quality of this environment is a critical step for preventing early obesity.

\section{Acknowledgments}

We thank the participating families and the Infant Care Team. This research was supported by NIH/NICHD Grant No. 5-R01 HD042219-02 (PI: Bentley); the Nutritional Epidemiology Core of the Clinical Nutrition Research Center at UNC, Grant Number: DK56350; and the Carolina Population Center (5 R24 HD050924 from the Eunice Kennedy Shriver National Institute of Child Health and Human Development (NICHD))

\section{References}

Agostoni C. Ghrelin, leptin and the neurometabolic axis of breastfed and formula-fed infants. Acta Paediatrica. 2005; 94(5):523-525. [PubMed: 16188736]

Alwin DF, Wray LA. A life-span developmental perspective on social status and health. Journal of Gerontology B Psychological Sciences and Social Sciences. 2005; 60(Special Issue 2):7-14.

American Academy of Pediatrics. Pediatric nutrition handbook. American Academy of Pediatrics; Elk Grove Village, IL: 2008.

Arenz S, Ruckerl R, Koletzko B, von Kries R. Breast-feeding and childhood obesity-a systematic review. International Journal of Obesity and Related Metabolic Disorders. 2004; 28(10):1247-1256. [PubMed: 15314625]

Asiodu I, Flaskerud JH. Got milk? A look at breastfeeding from an African American perspective. Issues in Mental Health Nursing. 2011; 32(8):544-546. [PubMed: 21767257]

Avery AB, Magnus JH. Expectant fathers' and mothers' perceptions of breastfeeding and formula feeding: a focus group study in three US cities. Journal of Human Lactation. 2011; 27(2):147-154. [PubMed: 21393504]

Baughcum AE, Burklow KA, Deeks CM, Powers SW, Whitaker RC. Maternal feeding practices and childhood obesity: a focus group study of low-income mothers. Archives of Pediatrics \& Adolescent Medicine. 1998; 152(10):1010-1014. [PubMed: 9790612]

Ben-Shlomo Y, Kuh D. A life course approach to chronic disease epidemiology: conceptual models, empirical challenges and interdisciplinary perspectives. International Journal of Epidemiology. 2002; 31(2):285-293. [PubMed: 11980781]

Bentley ME, Dee DL, Jensen JL. Breastfeeding among low income, African-American women: power, beliefs and decision making. The Journal of Nutrition. 2003; 133(1):305S-309S. [PubMed: 12514315]

Bentley ME, Gavin L, Black MM, Teti L. Infant feeding practices of low-income, African-American, adolescent mothers: an ecological, multigenerational perspective. Social Science \& Medicine. 1999; 49(8):1085-1100. [PubMed: 10475672]

Benyshek DC. The developmental origins of obesity and related health disorders-prenatal and perinatal factors. Collegium Antropologicum. 2007; 31(1):11-17. [PubMed: 17598381]

Birch LL, Fisher JO. Development of eating behaviors among children and adolescents. Pediatrics. 1998; 101(3 Pt 2):539-549. [PubMed: 12224660]

Braveman P. A health disparities perspective on obesity research. Preventing Chronic Disease. 2009; 6(3):A91. [PubMed: 19527592]

Burdette H, Whitaker RC, Hall WC, Daniels SR. Breastfeeding, introduction of complementary foods, and adiposity at 5 years of age. American Journal of Clinical Nutrition. 2006; 83(3):550-558. [PubMed: 16522900]

Celi AC, Rich-Edwards JW, Richardson MK, Kleinman KP, Gillman MW. Immigration, race/ ethnicity, and social and economic factors as predictors of breastfeeding initiation. Archives of Pediatrics \& Adolescent Medicine. 2005; 159(3):255-260. [PubMed: 15753269]

Corbett KS. Explaining infant feeding style of low-income black women. Journal of Pediatric Nursing. 2000; 15(2):73-81. [PubMed: 10808622] 
Cricco-Lizza R. Infant-feeding beliefs and experiences of Black women enrolled in WIC in the New York metropolitan area. Qualitative Health Research. 2004; 14(9):1197-1210. [PubMed: 15448295]

Dennis CL, McQueen K. Does maternal postpartum depressive symptomatology influence infant feeding outcomes? Acta Paediatrica. 2007; 96(4):590-594. [PubMed: 17391475]

Dietz WH. Childhood weight affects adult morbidity and mortality. The Journal of Nutrition. 1998; 128(2 Suppl):411S-414S. [PubMed: 9478038]

Forste R, Weiss J, Lippincott E. The decision to breastfeed in the United States: does race matter? Pediatrics. 2001; 108(2):291-296. [PubMed: 11483790]

Gartstein M, Rothbart M. Studying infant temperament via the revised infant behavior questionnaire. Infant Behavior and Development. 2003; 26(1):64-86.

Gillman MW. Developmental origins of health and disease. The New England Journal of Medicine. 2005; 353(17):1848-1850. [PubMed: 16251542]

Grummer-Strawn LM, Mei Z. Does breastfeeding protect against pediatric overweight? Analysis of longitudinal data from the centers for disease control and prevention pediatric nutrition surveillance system. Pediatrics. 2004; 113(2):e81-86. [PubMed: 14754976]

Haider, S.; Jacknowitz, A.; Schoeni, RF. Welfare work requirements and individual well-being: evidence from the effects on breastfeeding. Rand; Santa Monica, CA: 2002.

Heinig MJ, Follett JR, Ishii KD, Kavanagh-Prochaska K, Cohen R, Panchula J. Barriers to compliance with infant-feeding recommendations among low-income women. Journal of Human Lactation. 2006; 22(1):27-38. [PubMed: 16467285]

Hendricks K, Briefel R, Novak T, Ziegler P. Maternal and child characteristics associated with infant and toddler feeding practices. Journal of the American Dietetic Association. 2006; 106(1 Suppl 1):S135-S148. [PubMed: 16376637]

Horodynski MA, Stommel M, Brophy-Herb H, Xie Y, Weatherspoon L. Low-income African American and non-Hispanic White mothers' self-efficacy, "picky eater" perception, and toddler fruit and vegetable consumption. Public Health Nursing. 2010; 27(5):408-417. [PubMed: 20840710]

Huh SY, Rifas-Shiman SL, Taveras EM, Oken E, Gillman MW. Timing of solid food introduction and risk of obesity in preschool-aged children. Pediatrics. 2011; 127(3):e544-551. [PubMed: 21300681]

Hurley KM, Black MM, Papas MA, Caufield LE. Maternal symptoms of stress, depression, and anxiety are related to nonresponsive feeding styles in a statewide sample of WIC participants. The Journal of Nutrition. 2008; 138(4):799-805. [PubMed: 18356338]

Kaufman L, Deenadayalan S, Karpati A. Breastfeeding ambivalence among low-income African American and Puerto Rican women in north and central Brooklyn. Maternal and Child Health Journal. 2010; 14(5):696-704. [PubMed: 19644744]

Koletzko B, von Kries R, Closa R, Escribano J, Scaglioni S, Giovannini M, et al. Can infant feeding choices modulate later obesity risk? American Journal of Clinical Nutrition. 2009; 89(5):1502S1508S. [PubMed: 19321574]

Kumanyika SK. Environmental influences on childhood obesity: ethnic and cultural influences in context. Physiology \& Behavior. 2008; 94(1):61-70. [PubMed: 18158165]

Laraia BA, Borja JB, Bentley ME. Grandmothers, fathers, and depressive symptoms are associated with food insecurity among low-income first-time African-American mothers in North Carolina. Journal of the American Dietetic Association. 2009; 109(6):1042-1047. [PubMed: 19465186]

Li R, Darling N, Maurice E, Barker L, Grummer-Strawn LM. Breast-feeding rates in the United States by characteristics of the child, mother, or family: the 2002 National Immunization Survey. Pediatrics. 2005; 115(1):e31-e37. [PubMed: 15579667]

McCann MF, Baydar N, Williams RL. Breastfeeding attitudes and reported problems in a national sample of WIC participants. Journal of Human Lactation. 2007; 23(4):314-324. [PubMed: 17991796]

McLearn KT, Minkovitz CS, Strobino DM, Marks E, Hou W. Maternal depressive symptoms at 2 to 4 months post partum and early parenting practices. Archives of Pediatrics \& Adolescent Medicine. 2006a; 160(3):279-284. [PubMed: 16520447] 
McLearn KT, Minkovitz CS, Strobino DM, Marks E, Hou W. The timing of maternal depressive symptoms and mothers' parenting practices with young children: implications for pediatric practice. Pediatrics. 2006b; 118(1):e174-e182. [PubMed: 16818531]

Mahoney MC, James DM. Predictors of anticipated breastfeeding in an urban, low-income setting. The Journal of Family Practice. 2000; 49(6):529-533. [PubMed: 10923553]

Moorcroft KE, Marshall JL, McCormick FM. Association between timing of introducing solid foods and obesity in infancy and childhood: a systematic review. Maternal \& Child Nutrition. 2011; 7(1):3-26. [PubMed: 21143583]

Noel-Weiss J, Rupp A, Cragg B, Bassett V, Woodend AK. Randomized controlled trial to determine effects of prenatal breastfeeding workshop on maternal breastfeeding self-efficacy and breastfeeding duration. Journal of Obstetric, Gynecologic, and Neonatal Nursing. 2006; 35(5): $616-624$.

Ogden CL, Carroll MD, Curtin LR, McDowell MA, Tabak CJ, Flegal KM. Prevalence of overweight and obesity in the United States, 1999-2004. JAMA. 2006; 295(13):1549-1555. [PubMed: 16595758]

Ogden CL, Kuczmarski RJ, Flegal KM, Mei Z, Guo S, Wei R, et al. Centers for disease control and prevention 2000 growth charts for the United States: improvements to the 1977 national center for health statistics version. Pediatrics. 2002; 109(1):45-60. [PubMed: 11773541]

Ong KK, Emmett PM, Noble S, Ness A, Dunger DB. Dietary energy intake at the age of 4 months predicts postnatal weight gain and childhood body mass index. Pediatrics. 2006; 117(3):e503e508. [PubMed: 16510629]

Owen CG, Martin RM, Whincup PH, Smith GD, Cook DG. Effect of infant feeding on the risk of obesity across the life course: a quantitative review of published evidence. Pediatrics. 2005; 115(5):1367-1377. [PubMed: 15867049]

Perez-Escamilla R, Bermudez O. Early life nutrition disparities: where the problem begins? Advances in Nutrition. 2012; 3(1):71-72. [PubMed: 22332104]

Polhamus, B.; Dalenius, K.; Borland, E.; Mackintosh, H.; Smith, B.; Grummer-Strawn, L. Pediatric nutrition surveillance 2007 report. U.S. department of health and human services, centers for disease control and prevention; Atlanta: 2009.

Ponza M, Devaney B, Ziegler P, Reidy K, Squatrito C. Nutrient intakes and food choices of infants and toddlers participating in WIC. Journal of the American Dietetic Association. 2004; 104(1 Suppl 1):s71-s79. [PubMed: 14702021]

Radloff L. The CES-D scale: a self-report depression scale for research in the general population. Applied Psychological Measurement. 1977; 1(3):385-401.

Robinson KM, VandeVusse L. African American women's infant feeding choices: prenatal breastfeeding self-efficacy and narratives from a black feminist perspective. The Journal of Perinatal \& Neonatal Nursing. 2011; 25(4):320-328. quiz 329-330. [PubMed: 22071615]

Saelens BE, Sallis JF, Black JB, Chen D. Neighborhood-based differences in physical activity: an environment scale evaluation. American Journal of Public Health. 2003; 93(9):1552-1558. [PubMed: 12948979]

Savage JS, Fisher JO, Birch LL. Parental influence on eating behavior: conception to adolescence. The Journal of Law, Medicine \& Ethics. 2007; 35(1):22-34.

Scanlon K, Grummer-Strawn L, Li R, Chen J, Molinari N, Perrine C. Racial and ethnic differences in breastfeeding initiation and duration, by state-national immunization survey, United States, 20042008. Morbidity and Mortality Weekly. 2010; 59(11):327-334.

Sharps PW, El-Mohandes AA, Nabil El-Khorazaty M, Kiely M, Walker T. Health beliefs and parenting attitudes influence breastfeeding patterns among low-income African-American women. Journal of Periodontalogy. 2003; 23(5):414-419.

Singh GK, Kogan MD, Dee DL. Nativity/immigrant status, race/ethnicity, and socioeconomic determinants of breastfeeding initiation and duration in the United States, 2003. Pediatrics. 2007; 119(Suppl 1):S38-S46. [PubMed: 17272583]

Skinner JD, Ziegler P, Ponza M. Transitions in infants' and toddlers' beverage patterns. Journal of the American Dietetic Association. 2004; 104(1 Suppl 1):s45-s50. [PubMed: 14702017] 
Slining M, Adair LS, Goldman BD, Borja JB, Bentley M. Infant overweight is associated with delayed motor development. The Journal of Pediatrics. 2010; 157(1):20-25. [PubMed: 20227724]

Smithers LG, Golley RK, Brazionis L, Lynch JW. Characterizing whole diets of young children from developed countries and the association between diet and health: a systematic review. Nutrition Reviews. 2011; 69(8):449-467. [PubMed: 21790612]

Taveras EM, Gillman MW, Kleinman K, Rich-Edwards JW, Rifas-Shiman SL. Racial/ethnic differences in early-life risk factors for childhood obesity. Pediatrics. 2010; 125(4):686-695. [PubMed: 20194284]

Thompson AL, Mendez MA, Borja JB, Adair LS, Zimmer CR, Bentley ME. Development and validation of the infant feeding style Questionnaire. Appetite. 2009; 53(2):210-221. [PubMed: 19576254]

Wasser H, Bentley M, Borja J, Davis Goldman B, Thompson A, Slining M, et al. Infants perceived as "fussy" are more likely to receive complementary foods before 4 months. Pediatrics. 2011; 127(2): 229-237. [PubMed: 21220398]

Weiss R, Dziura J, Burgert TS, Tamborlane WV, Taksali SE, Yeckel CW, et al. Obesity and the metabolic syndrome in children and adolescents. The New England Journal of Medicine. 2004; 350(23):2362-2374. [PubMed: 15175438]

Wright AL, Bauer M, Naylor A, Sutcliffe E, Clark L. Increasing breastfeeding rates to reduce infant illness at the community level. Pediatrics. 1998; 101(5):837-844. [PubMed: 9565411] 


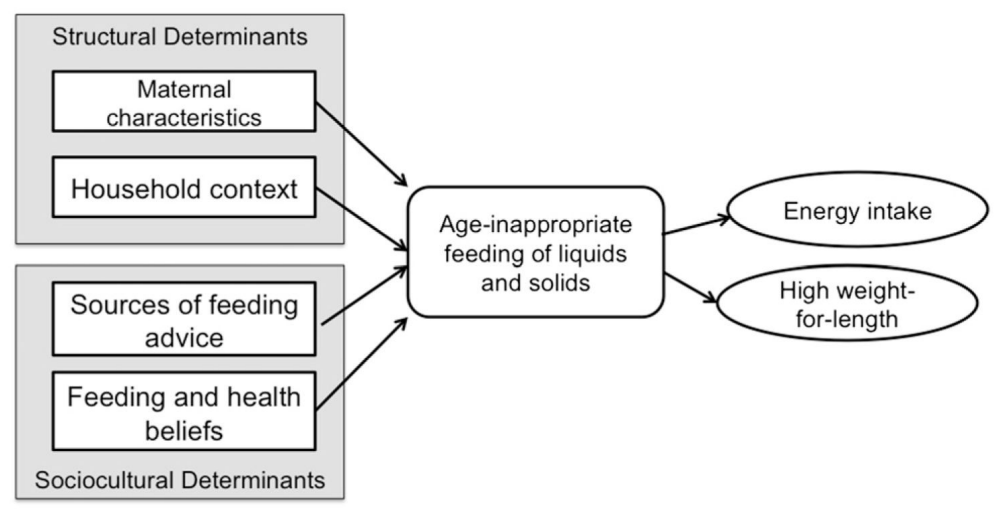

Fig. 1.

Conceptual model of the predictors and consequences of age-inappropriate feeding of solids and liquids. 


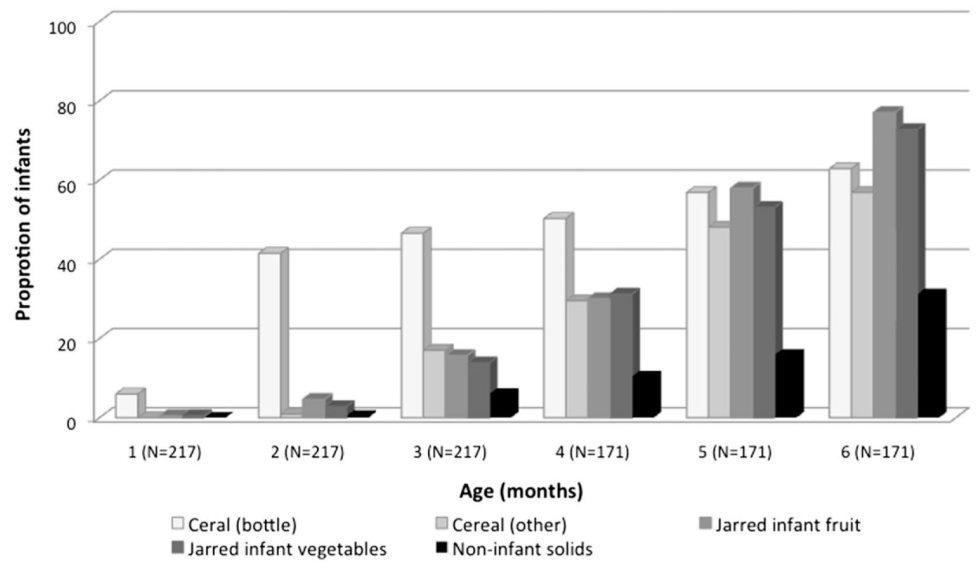

Fig. 2.

Solid foods provided to infants in the first 6 months of life. This figure shows the proportion of infants receiving each of the solid food categories during the first 6 months of life. 


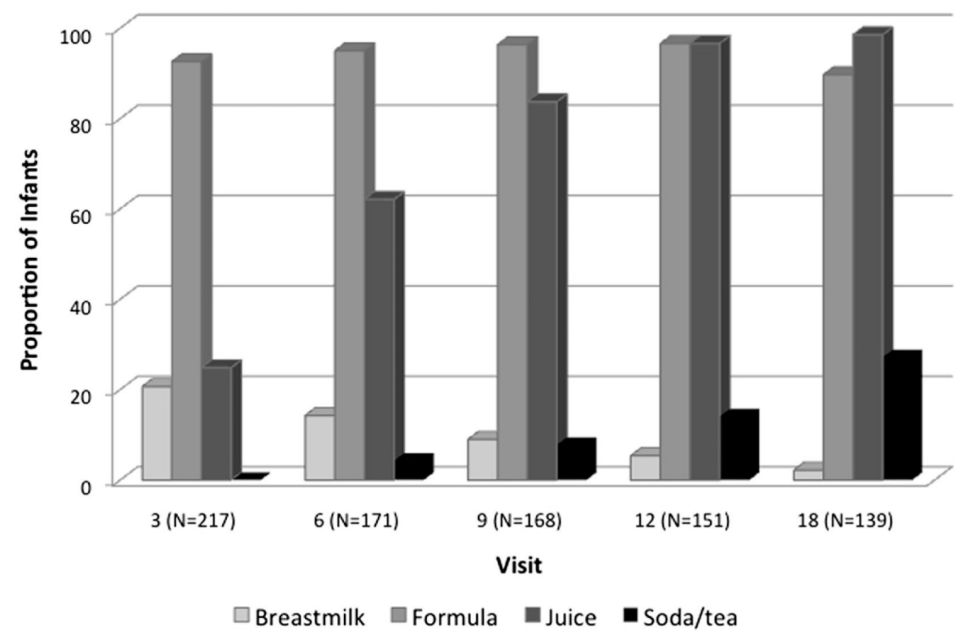

Fig. 3.

Liquids consumed by infants at 3-18 month visits. This figure shows the proportion of infants receiving breastmilk, formula, juice and soda/tea at each home visit. 
Table 1

Sample characteristics and longitudinal predictors of age-inappropriate feeding of solids and liquids ${ }^{a}$ over 318 months ( $n=211$ infants)

\begin{tabular}{|c|c|c|c|}
\hline & Baseline Mean (SD)/N(\%) ${ }^{b}$ & $\mathrm{OR}^{c}(95 \% \mathrm{CI})$ & $\begin{array}{l}\text { Full model } \mathrm{OR}^{d} \\
(95 \% \mathrm{CI})\end{array}$ \\
\hline \multicolumn{4}{|l|}{ Demographic and structural predictors } \\
\hline \multicolumn{4}{|l|}{ Model 1: maternal characteristics } \\
\hline $\mathrm{Age}^{e}$ & $22.7(3.8)$ & - & - \\
\hline Education ( tys grad) & $156(72.9 \%)$ & $1.10(0.75,1.61)$ & \\
\hline Obesity (BMI >30) & $96(44.2 \%)$ & $1.29(0.93,1.79)$ & \\
\hline Marital status (single) & $190(88.8 \%)$ & $1.81 *(1.04,3.15)$ & $1.83^{*}(1.02,3.30)$ \\
\hline Currently working & $115(53.74 \%)$ & $1.10(0.80,1.52)$ & \\
\hline Depressive symptoms $f$ & $62(29.11 \%)$ & $1.49^{*}(1.04,2.14)$ & $1.39(0.96,2.02)$ \\
\hline Model fit & & Wald $X^{2}(\mathrm{df} 8)=56.6, p<0.001$ & \\
\hline \multicolumn{4}{|l|}{ Model 2: Household characteristics } \\
\hline Household size ( $>4$ people) & $3.86(1.7)$ & $1.09(0.96,1.25)$ & \\
\hline Neighborhood safety $g$ & $1.9(0.5)$ & $1.33(0.95,1.87)$ & \\
\hline Food insecurity $h$ & $98(46 \%)$ & $0.89(0.69,1.13)$ & \\
\hline Baby's father present & $71(32.7 \%)$ & $0.68 *(0.46,0.99)$ & \\
\hline Baby's grandmother present & $88(40.6 \%)$ & $0.76(0.50,1.15)$ & \\
\hline Alternate caregiver feeds $>50 \%$ of meals & $115(53.5 \%)$ & $1.06(0.77,1.48)$ & \\
\hline Model fit & & Wald $X^{2}($ df 9$)=50.13, p<0.001$ & \\
\hline \multicolumn{4}{|l|}{ Model 3: Infant characteristics } \\
\hline Infant sex $(\text { male })^{e}$ & $101(46.5 \%)$ & - & - \\
\hline Low birth weight $(<2.5 \mathrm{~kg})$ & $14(6.5 \%)$ & $0.97(0.46,2.01)$ & \\
\hline Currently breastfed & $49(22.6 \%)$ & $0.48^{* *}(0.30,0.79)$ & $0.58^{*}(0.35,0.97)$ \\
\hline Model fit & & Wald $X^{2}($ df 5$)=53.44, p<0.001$ & \\
\hline \multicolumn{4}{|l|}{ Sociocultural determinants } \\
\hline \multicolumn{4}{|l|}{ Model 4: Sources of feeding advice } \\
\hline Mother & $139(65.3 \%)$ & $1.24(0.87,1.72)$ & \\
\hline Doctor & $163(75.8 \%)$ & $1.05(0.74,1.49)$ & \\
\hline Friends & $97(44.9 \%)$ & $1.02(0.87,1.73)$ & \\
\hline Books & $94(43.7 \%)$ & $1.23(0.87,1.73)$ & \\
\hline Model fit & & Wald $x^{2}(\mathrm{df} 7)=45.46, p<0.001$ & \\
\hline \multicolumn{4}{|l|}{ Model 5: Feeding beliefs $i$} \\
\hline $\mathrm{BM}$ is enough to fill a baby & $146(67.3 \%)$ & $0.76(0.54,1.06)$ & \\
\hline BF infants know when full & $40(18.4 \%)$ & $1.14(0.76,1.71)$ & \\
\hline BF infants won't become fat & $31(14.3 \%)$ & $0.97(0.60,1.55)$ & \\
\hline BF infants healthier & $87(40.1 \%)$ & $1.10(0.79,1.53)$ & \\
\hline BF infants smarter & $62(28.6 \%)$ & $0.94(0.65,1.35)$ & \\
\hline Infants fed too much will be fat & $98(45.2 \%)$ & $1.54^{* *}(1.13,2.07)$ & $1.59^{* *}(1.14,2.20)$ \\
\hline
\end{tabular}




\begin{tabular}{|c|c|c|c|}
\hline & Baseline Mean $(\mathrm{SD}) / N(\%)^{b}$ & $\mathrm{OR}^{c}(95 \% \mathrm{CI})$ & $\begin{array}{l}\text { Full model OR } \\
(95 \% \mathrm{CI})\end{array}$ \\
\hline Infants fed solids too soon will be fat & $62(28.6 \%)$ & $1.23(0.84,1.80)$ & \\
\hline Model fit & & Wald $X^{2}(\mathrm{df} 10)=56.35, p<0.001$ & \\
\hline \multicolumn{4}{|c|}{ Model 5: Beliefs about infant size and health ${ }^{i}$} \\
\hline Concern infant will be overweight & $26(12.2 \%)$ & $1.43(0.84,2.44)$ & \\
\hline Concern infant will be thin & $5(2.3 \%)$ & $1.47(0.64,3.38)$ & \\
\hline Fat infants are healthy & $14(6.5 \%)$ & $0.98(0.49,1.94)$ & \\
\hline Infant is a "greedy" baby & $106(49.6 \%)$ & $1.65^{* *}(1.21,2.26)$ & $1.70^{* *}(1.21,2.40)$ \\
\hline Infant will eat anything & $38(18.1 \%)$ & $0.63^{* *}(0.45,0.88)$ & $0.55^{* *}(0.39,0.79)$ \\
\hline Model fit & & Wald $x^{2}(\mathrm{df} 8)=64.52, p<0.001$ & $\begin{array}{l}\text { Wald } \chi^{2}(\text { df } 9)=72.94 \\
p<0.001\end{array}$ \\
\hline \multicolumn{3}{|l|}{$*<0.05$} & \\
\hline \multicolumn{4}{|c|}{$\begin{array}{l}\text { a Feeding is considered inappropriate if the infant received: at } 3 \text { months, any liquids or solids except for breastmilk or formula; at } 6 \text { months, cow's } \\
\text { milk or soy milk instead of human milk or formula, or juice, meat, eggs, cheese, junk food, fast food, or sweets; at } 9 \text { months, cow's milk or soy } \\
\text { milk, junk food, fast food or sweets; and at } 12 \text { or } 18 \text { months, flavored milks, junk food, fast food, or sweets based on AAP guidelines. }\end{array}$} \\
\hline \multicolumn{4}{|c|}{ 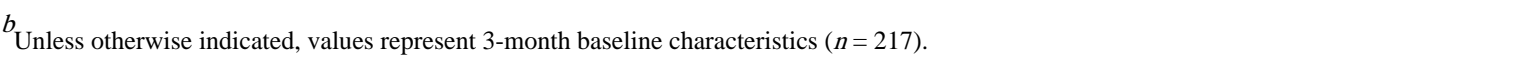 } \\
\hline \multicolumn{4}{|c|}{$\begin{array}{l}c \text { Results from mixed logistic regression models, controlling for all variables within the category, maternal age, infant age and sex, and repeated } \\
\text { measures across subjects. }\end{array}$} \\
\hline \multicolumn{4}{|c|}{$\begin{array}{l}\text { d Results from mixed logistic regression model, controlling for significant variables in component models, maternal age, infant age and sex, and } \\
\text { repeated measures across subjects. }\end{array}$} \\
\hline \multicolumn{4}{|l|}{${ }^{e}$ Covariate in adjusted model. } \\
\hline \multicolumn{4}{|c|}{$f_{\text {Score }}>16$ on the Center for Epidemiological Studies Depression Scale. } \\
\hline \multicolumn{4}{|c|}{$\begin{array}{l}{ }^{g} \text { Continuous score from the "Safety from Crime" component of the neighborhood environment walkability scale. Scores range from } 1 \text { to } 4 \text { with } \\
\text { higher scores indicating a safer neighborhood. }\end{array}$} \\
\hline
\end{tabular}


Table 2

Longitudinal models examining the concurrent relationship between age-inappropriate feeding and energy intake and risk of infant overweight

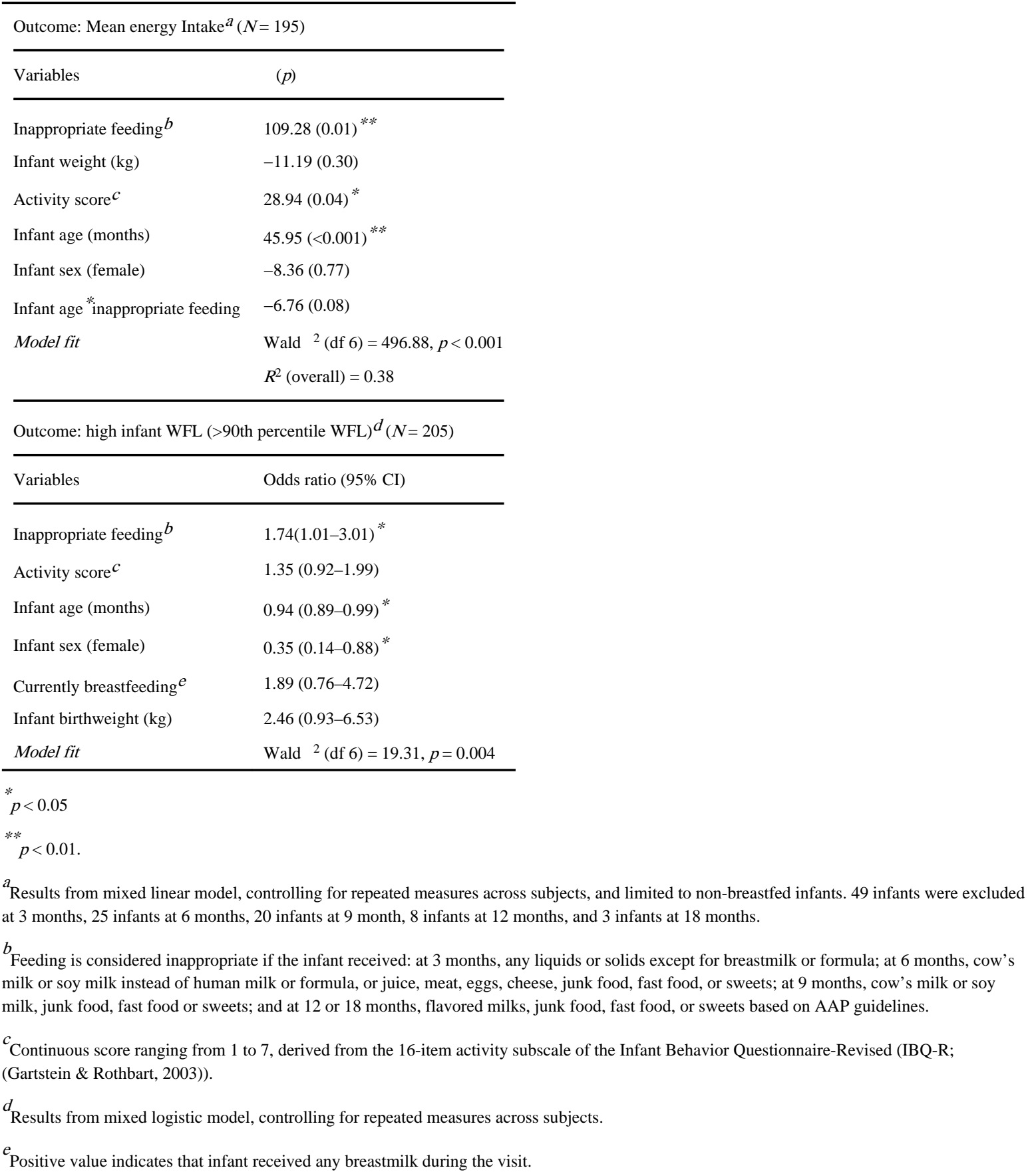

